\title{
ELECTROPHYSIOLOGICAL OBSERVATIONS OF UTERINE MOTILITY DURING THE OESTROUS CYCLE IN SHEEP
}

\author{
C. NAAKTGEBOREN, * G. G. VAN DER WEYDEN, $\uparrow$ \\ P. J. KLOPPER, $\ddagger$ C. H. KROON,* A. G. SCHOOF* AND \\ M. A. M. TAVERNE $\uparrow$ \\ * Obstetrical Clinic and $\ddagger$ Department of Experimental Surgery, University Hospital, \\ Wilhelmina Gasthius, 1e Helmersstraat 104, Amsterdam, and \\ $\uparrow$ Clinic for Veterinary Obstetrics, State University, Yalelaan, Utrecht, \\ Netherlands
}

\section{(Received 22nd November 1972)}

\begin{abstract}
Summary. The electrophysiological activity of sheep myometrium was recorded by means of implantable electrodes and an implantable contact plug. The method is described in detail and the advantages are discussed. During the oestrous cycle, the activity pattern changed considerably. The greatest activity was observed at the time of oestrus.

The amplitudes were $200 \mu \mathrm{V}$ or more, and the pattern was rhythmic and regular. Most contractions were peristaltic. One day later, most contractions were propagated in the opposite direction and long pauses occurred from time to time. The endocrine basis of the changes in myometrial activity as well as their biological relevance are discussed and compared with data from the literature.
\end{abstract}

\section{INTRODUCTION}

The pattern of uterine motility undergoes marked changes during the human menstrual cycle. Moawad \& Bengtsson (1967) used sponge-tipped open-end catheters for intrauterine pressure recording in women. They found the following patterns in normal, regular 28-day cycles. From Day 6 to Day 18, the contractions were frequent (two to four/min) but of low amplitude ( 3 to $10 \mathrm{~mm}$ $\mathrm{Hg}$ ). From the 8th day before the next menstruation, the pattern was characterized by less frequent (one every 2 or $3 \mathrm{~min}$ ) but stronger contractions (up to $25 \mathrm{~mm} \mathrm{Hg}$ ). These contractions increased in amplitude and reached a prelabourlike pattern 4 days before the next period. At the onset of bleeding, a labour-like activity was observed. Zerobin (1968) studied uterine activity in the pig by various techniques. He recorded intrauterine pressure changes with open-end catheters and microballoons and the electrical activity of the myometrium with silver electrodes. All records were made under full anaesthesia. Zerobin concluded that the frequency, the duration and the amplitude of the uterine contractions were dependent upon the endocrine balance in the animal. During 'interoestrus, prooestrus and postoestrus' (terms used by Zerobin) only contrac- 
tions of small amplitude were observed. Strong contractions, which were mainly propagated from the tube in a cervical direction, occurred on the 1st and 3rd day of heat but on the 2nd day most contractions ran in the opposite direction and the quickest propagation was observed.

Döcke \& Worch (1963) found that the greatest activity in the sow occurred when the uterus was under oestrogen domination whereas during the luteal phase, the contractions were feeble. At the stage of greatest development of the CL, no effective myometrial activity could be recorded.

Myometrial activity in cattle was studied by Döcke $(1958,1962)$. He demonstrated a clear relation between the motility pattern and the phase of the oestrous cycle. During oestrus, a maximal rhythmic activity occurred but, in dioestrus, a lesser arrhythmic activity was recorded. During oestrus and immediately after oestrus, the contractions ran from the cervix in a tubal direction, whereas they ran from the tubes towards the cervix at the end of postoestrus and during pro-oestrus. At dioestrus, the uterus displayed only local contractions. Döcke carried out his investigations in unanaesthetized animals but he inserted his catheters from the vagina into the uterine cavity just before recording. He used only closed catheters for pressure recordings.

We have investigated the changes in uterine motility during the oestrous cycle in unanaesthetized sheep by recording the electrical activity of the myometrium. A great advantage of this method is that it allows numerous recordings to be made from the same animal, which can act as its own control. Since the electrodes are attached to the uterine wall at operation, it is certain that all records are taken from the same parts of the uterus, which facilitates comparison of different records from the same animal. As far as we know, the changes of uterine activity during the oestrous cycle in ruminants have not previously been studied in this way. Since the electrical phenomena are closely related to the initiation of contractions and their propagation by the myometrium, we believe that electrophysiological studies may contribute substantially to an understanding of changes in the activity pattern and give more information than records of intrauterine pressure changes alone (Naaktgeboren, 1973).

\section{MATERIALS AND METHODS}

Investigations were carried out on seven ewes of the Texel breed during the breeding season. The date of the last oestrus before the operation was known. At operation, the ovaries were carefully observed in order to ascertain the stage of the oestrous cycle at the start of the experiment. After the experiment, the animals were killed and a careful autopsy was carried out. Histological sections of different parts of the uterus were prepared and studied in order to determine the influence of the electrodes on the uterine tissues.

Under fluothane anaesthesia, four pairs of electrodes were placed on the myometrium (two pairs on each uterine horn) and sutured to the uterine wall. The silver electrodes had a length of $5 \mathrm{~mm}$ and were fixed on a small plate at a constant distance of 5 or $10 \mathrm{~mm}$ from each other. Both sides of the plate were covered with silastic sheets (Silastic Dow Corning) and the cables were embedded in silastic tubes. The whole assemblage was dipped in silastic elastomer. 
The cables were connected with a gold-lined 8-pin plug, which was fixed in a Pavlov cannula of stainless steel (Pl. 1, Fig. 1). It was of great importance to avoid rough portions on the silastic parts and to ensure good polymerization of the elastomer, otherwise there was a great risk of severe adhesion of internal organs to the silastic parts and secondarily to each other. Before the operation, the whole set was sterilized with ethylene dioxide.

Insertion of the Pavlov cannula into the abdominal wall did not seem to cause any suffering to the ewe. At recording, it was very simple to make contact by plugging the cables running from the recorder into the contact set (Pl. 1, Fig. 2).

A connection was thus established with the four universal preamplifiers (Elema-Schönander EMT 12) and the tracings were made by an ink-jet recorder (Elema-Schönander Mingograf 81), at different paper speeds, most frequently 5 or $10 \mathrm{~mm} / \mathrm{sec}$. The amplifiers were set at $30 \mathrm{Herz}$, with a time constant of $0.03 \mathrm{sec}$, which empirically has proved to give the best results. We have also used this method with good results in non-pregnant, pregnant, parturient and post-partum rabbits, dogs and sheep. By making notes about the animal's behaviour on the record, it was possible to study behavioural and environmental influences on the uterine activity pattern (Naaktgeboren, 1973). The animals behaved absolutely normally under the experimental conditions described and showed no signs of distress due to the surgical procedures. In one ewe, sixty-five records were obtained during a period of 12 weeks. The fact that the pattern of activity changed, and that the original pattern returned several times at cyclic intervals as described below, proves that the method is highly reliable for studies of uterine activity in vivo over quite long periods (Plates 2 to 5 ). Since the animal is used as its own control, it is possible to perform meaningful research on only a few animals. This is a great advantage if animal housing problems arise or if it is necessary to work with expensive experimental animals. This method, or a similar one, was used by Larks, Larks, Hoffer \& Charlson (1972) in studies of tubal activity in the goat, by several authors studying uterine activity (Naaktgeboren, 1973) and by Kelly, Code \& Elveback (1969) while studying the activity of the gastrointestinal tract.

At autopsy, we found that a capsule of connective tissue had been formed over the electrodes. The uterus and other internal organs had a normal and healthy appearance. The ovaries were also normal in appearance and it seems certain that their function was not disturbed.

The histological investigation of the uterus demonstrated that the serosa was three to four times thicker under the plate with the electrodes than in the control sections. The myometrium was not damaged and the endometrium was normal. In one ewe, killed $2 \frac{1}{2}$ weeks after operation, many neutrophil leucocytes with polymorphic nuclei in different stages were found near the sutures, but in another ewe, killed 2 months after the operation, this reaction could not be observed. Some individual data about the animal from which the records of Plates 2 to 5 are reproduced, may be of importance for the interpretation of the results.

Sheep no. 10 was in oestrus on 3rd November 1971 and the electrodes were introduced on 8th November 1971. At the operation, the right ovary exhibited a 
CL approximately 2 days old. The pairs of electrodes were placed at the tubal end of each uterine horn and near the corpus uteri. All reproduced tracings are from this animal. From top to bottom, the tracings represent the left horn at the tubal end, left horn near the corpus uteri, right horn at the tubal end, and the right horn near the corpus uteri. Sixty-five recordings were obtained and the animal was killed on 8th February 1972. At that time, the left ovary contained no large follicles while the right ovary exhibited a red CL approximately 1 or 2 days old.

Three ewes were studied during the breeding season 1971-72 and four animals during the autumn of 1972 at the onset of the breeding season. In these animals, oestrous behaviour could be detected with the aid of a vasectomized ram. In all seven animals, the duration of the oestrous cycle was 17 days, which is the normal length of the oestrous cycle in the sheep. In one animal, laparoscopic observations of uterine activity were made during oestrus but, due to technical difficulties, it was not possible to do this while simultaneously recording the electrical activity. Although the tracings of Plates 2 to 5 are reproduced from one animal, our conclusions are derived from the records of all seven ewes. The results from the seven animals were very similar.

\section{RESULTS}

The electrical activity of the sheep uterus was found to vary considerably during the course of the oestrous cycle. Most frequently, a diffuse pattern with low amplitudes, i.e. less than $50 \mu \mathrm{V}$, was recorded, although sometimes there was an indication of a slight rhythmicity (tracings 2, 9, 10, 12, 14). From time to time, the uterus displayed a very rhythmic and regular pattern of activity with much larger amplitudes, up to 250 to $500 \mu \mathrm{V}$ (tracings 4, 5, 13 and 15). Intermediate

\section{EXPLANATION OF PLATES}

\section{PLATE 1}

Fig. 1. This figure shows the set of four pairs of implantable electrodes, fixed on a plate covered with silastic sheets which are partially cut away before implantation. The remaining parts are used for sewing the plate with electrodes to the myometrium. The cables are embedded in silastic tubes and connected with an 8-pin gold-lined plug, fixed in a Pavlov cannula of stainless steel.

FIG. 2. To record uterine activity, the cables running from the universal preamplifiers are plugged into the contact set, which is implanted in the ewe's abdominal wall.

\section{PLATES 2 TO 5}

Electrical activity of the myometrium during the oestrous cycle in sheep (for explanation see text). Plate 2: tracings 1, 2, 3 and 4. Plate $3:$ tracings 5, 6, 7 and 8 . Plate $4:$ tracings 9 , 10,11 and 12. Plate $5:$ tracings 13,14 and 15 . Of the eight channels of the recorder, only four were used. Due to technical difficulties, in tracing 1 , only two channels and in tracings 2 and 3, only three channels gave a good record. From top to bottom, the recording channels represent the left uterine horn at the tubal end, the left horn near the corpus uteri, the right horn at the tubal end and the right horn near the corpus uteri. The time scale is marked in seconds. Tracings 2, 8, 9, 13 and 14 were recorded at a paper speed of $10 \mathrm{~mm} / \mathrm{sec}$. Tracings $1,3,4,11$ and 12 were recorded at $5 \mathrm{~mm} / \mathrm{sec}$ and tracings $5,6,7$ and 15 at $2.5 \mathrm{~mm} / \mathrm{sec}$. In all tracings, scales are shown on the left side. The line, originally $3 \mathrm{~cm}$ long, represents in most cases $100 \mu \mathrm{V}$. If the amplitudes are large, a $200 \mu \mathrm{V}$ mark is used. Tracings 4 and 5 are from the same record, but not continuous. Tracings 6 and 7 are continuous, whereas tracing 8 is from the same record but not continuous. In Textfig. 1, the numbers of the curves can easily be compared with the date of recording and the approximate stage of the oestrous cycle. 
PIATTE I

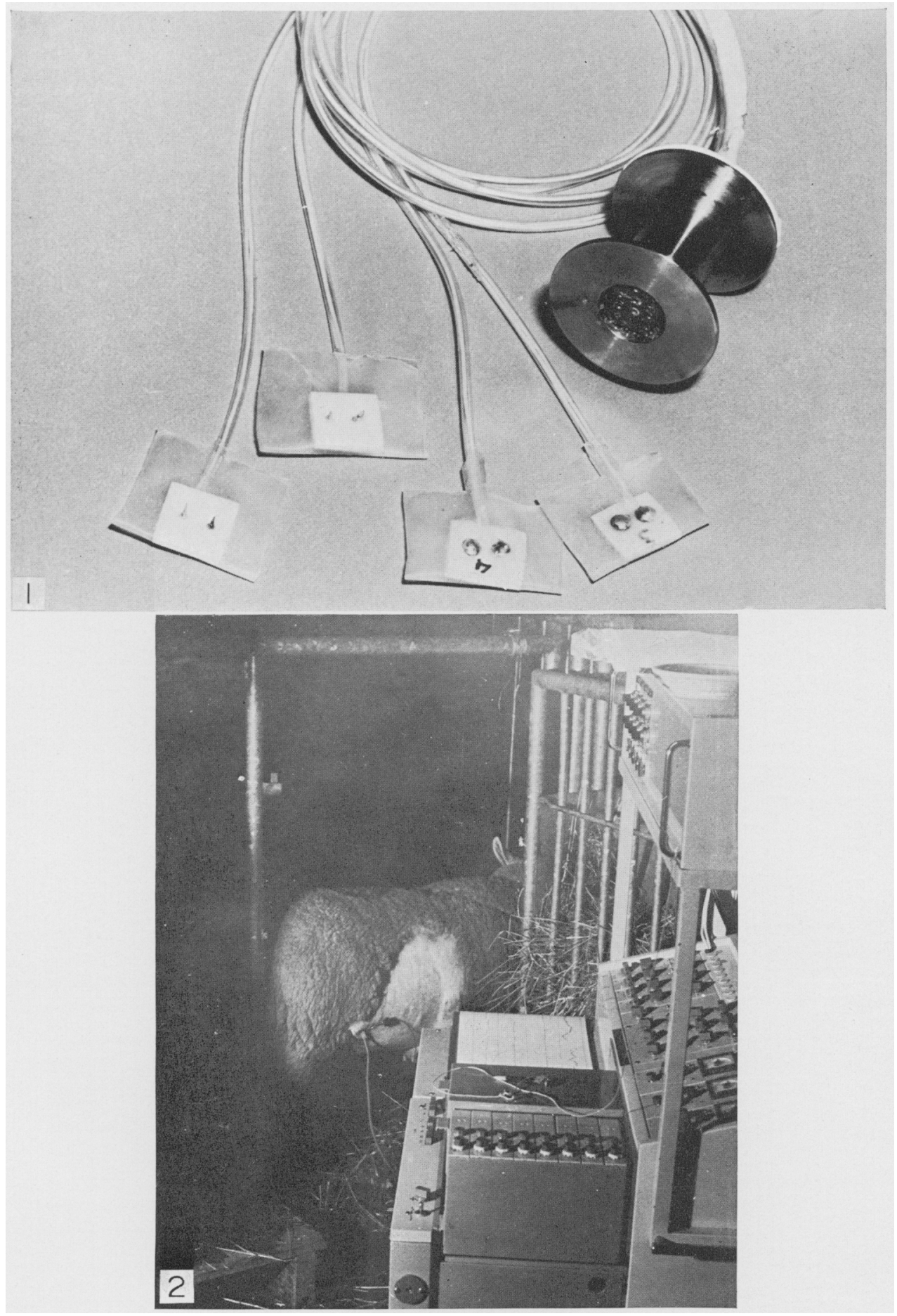

(Facing p. 514) 
PLATE 2

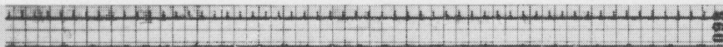

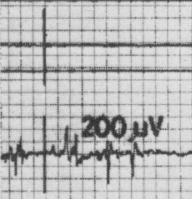

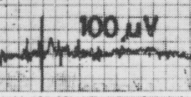

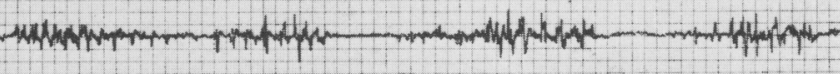

mimatim

(1)

1.

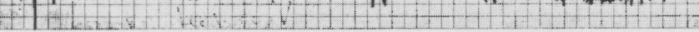

$\int+100 \mu \mathrm{V}$

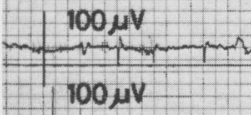

-

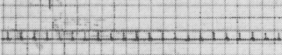

$+\infty$

$\mathrm{H}_{100 \mu \mathrm{V}}^{100 \mathrm{n}}$

\section{$100 \mu \mathrm{V}$}

T

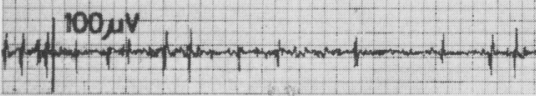

100

$00 \mathrm{~N}^{\mathrm{s}}$

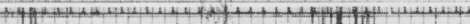

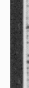

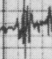

ify 4
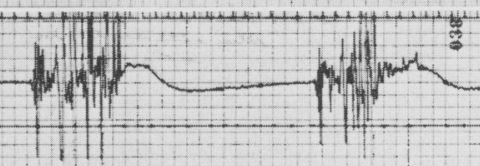

fillatht

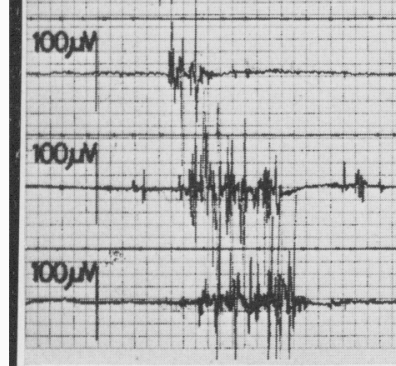

Whe $\lim +x+4+4$

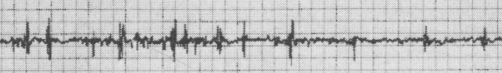
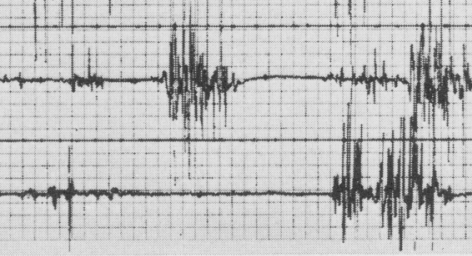

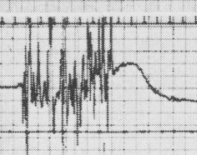

Whithing $+4 \|^{2}$ whint?

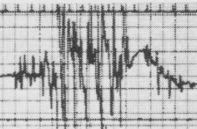

I!

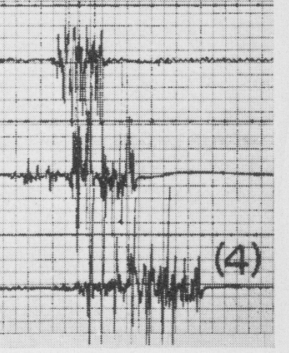


PLATE 3

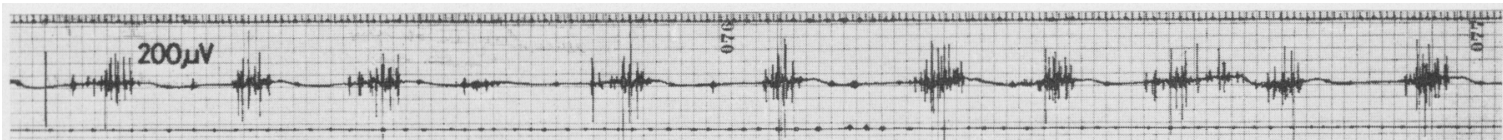

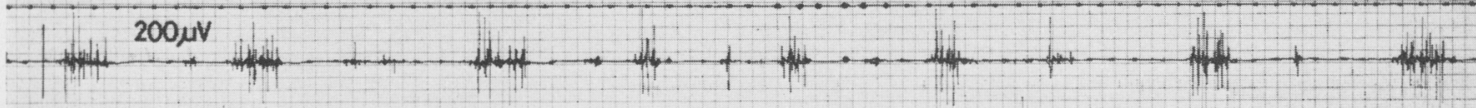

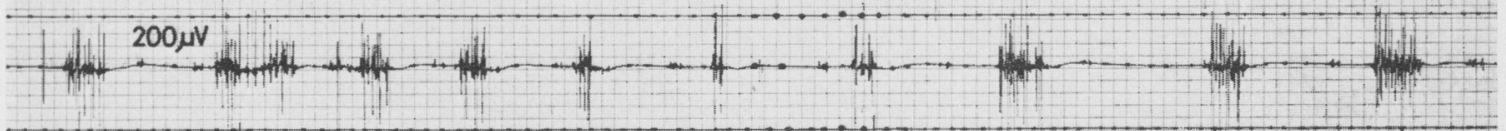

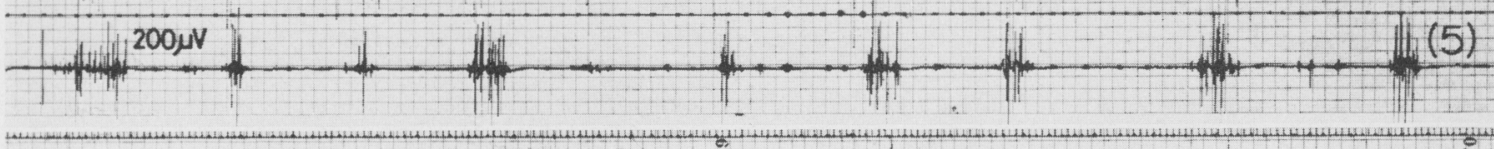
$200 \mu \mathrm{V}$ क्ष

$200 \mu \mathrm{V}$

$200 \mu \mathrm{V}$

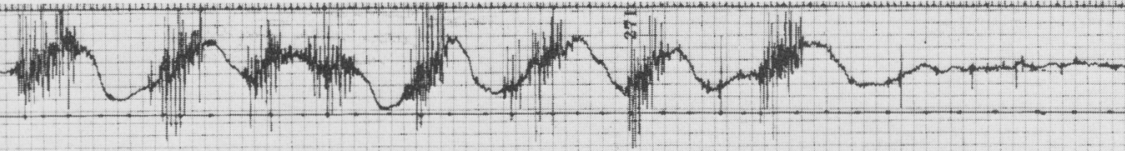

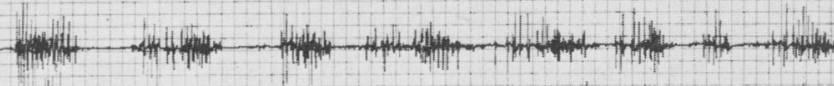

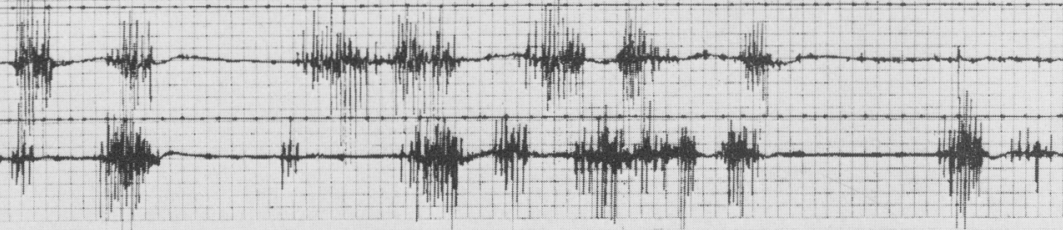

$\underbrace{200 \mu \mathrm{VV}}$

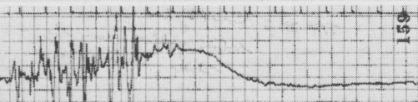

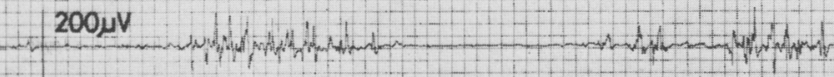

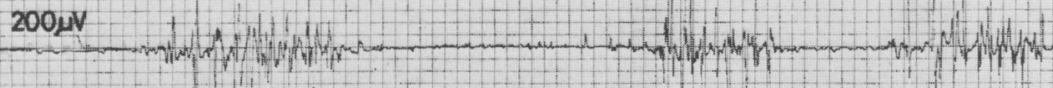

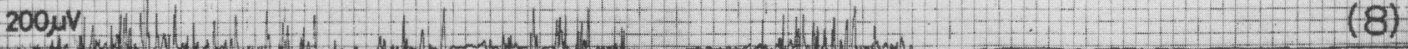

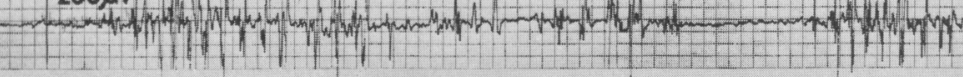


PLATE 4

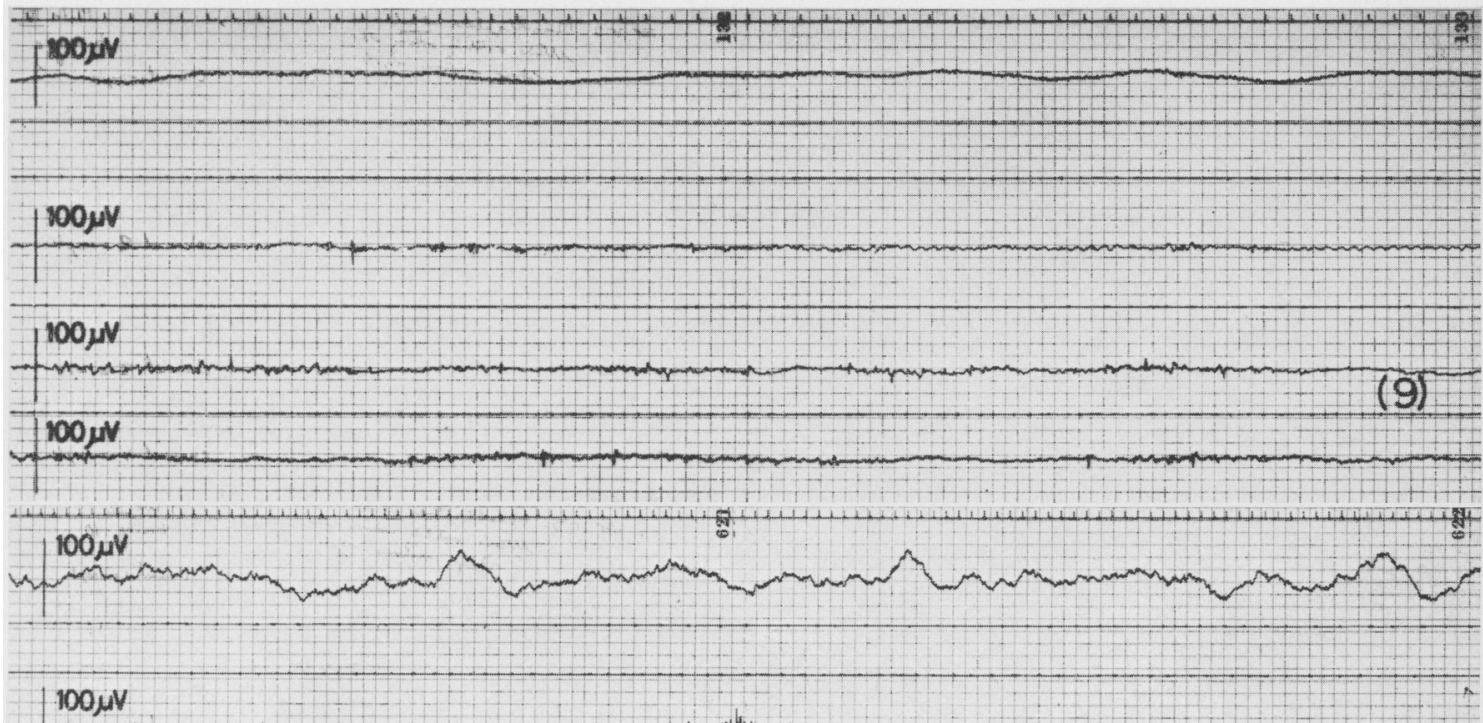

$100 \mu \mathrm{V}$

$100 \mu \mathrm{v}$

(10)

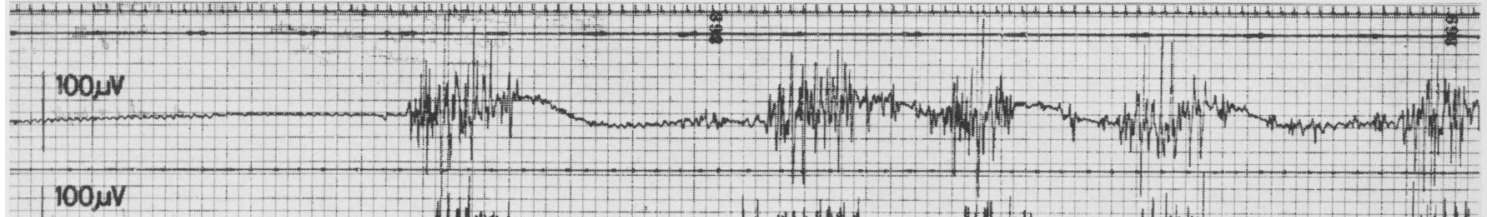

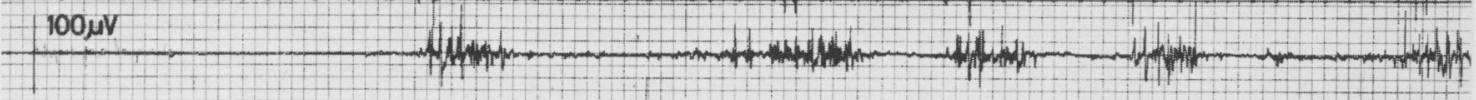

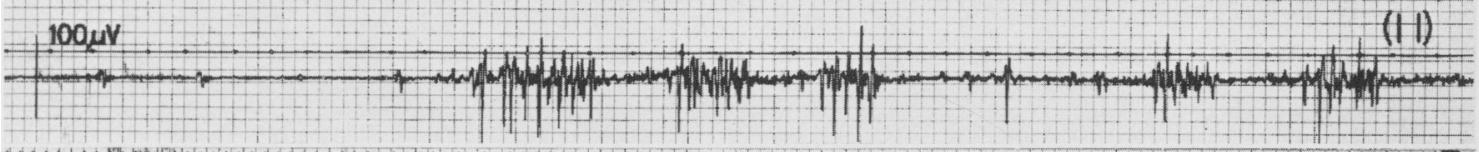

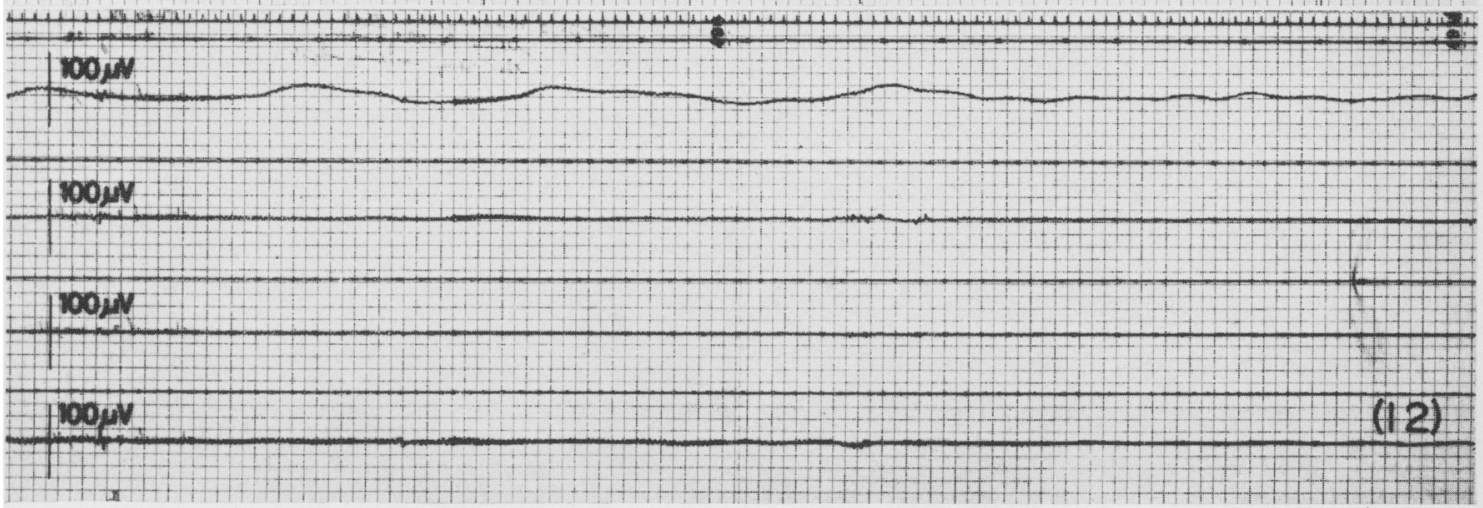


PLATE 5

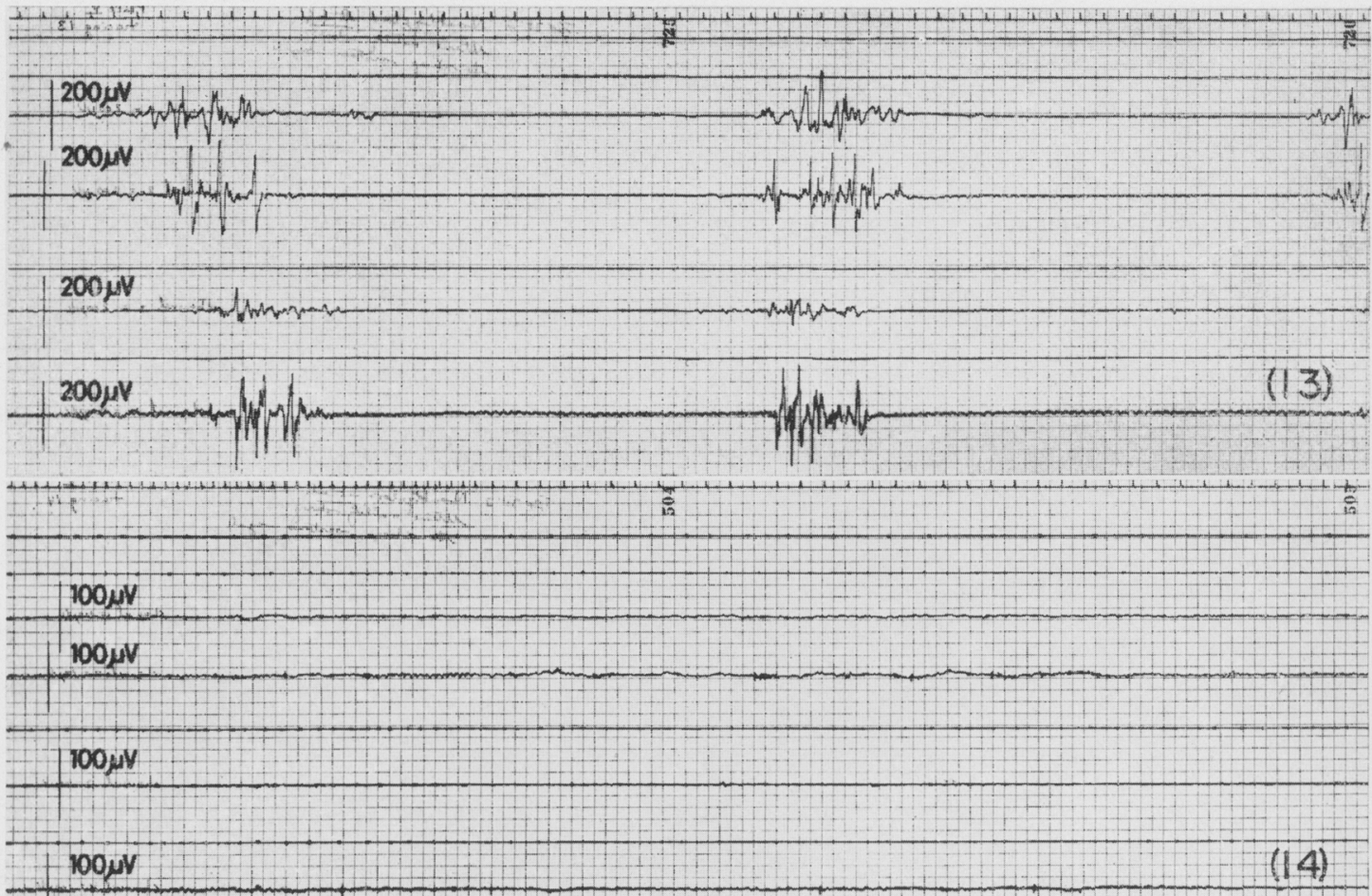

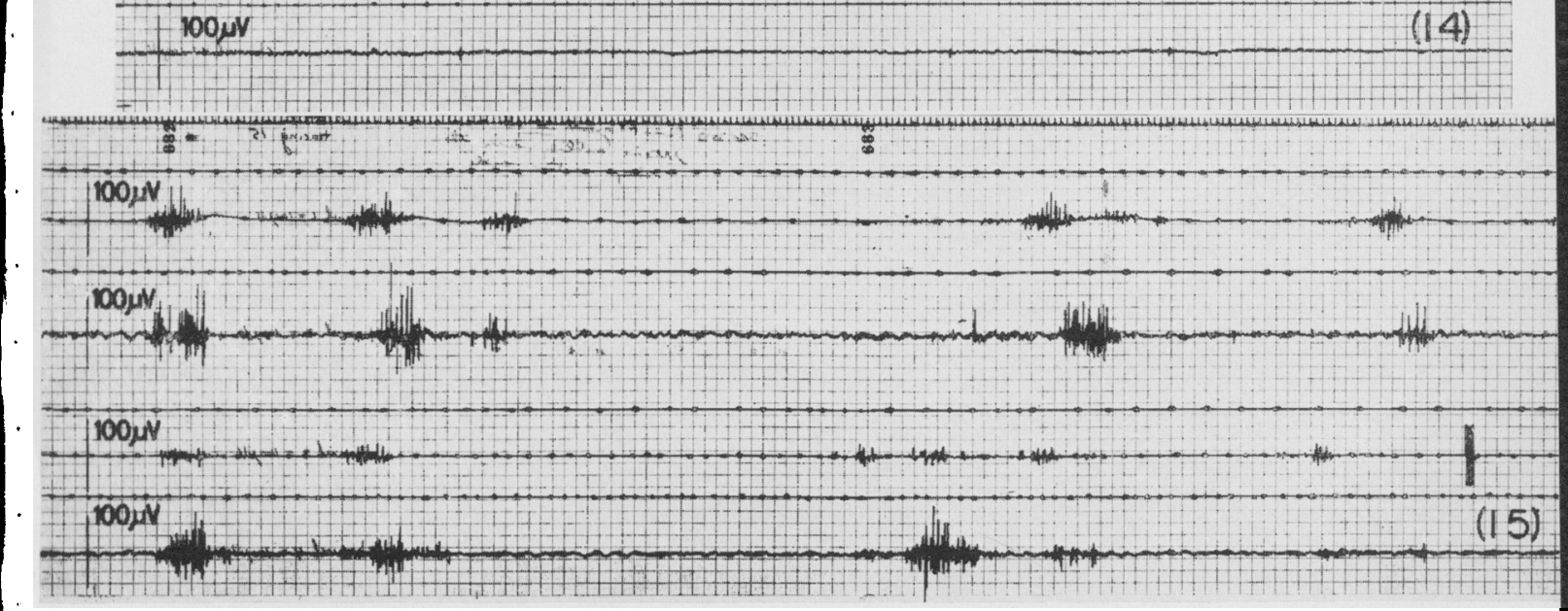


patterns also occurred (tracings $1,3,6,7,8$ and 11). Following a period with a diffuse pattern of electrical activity (tracing 2), the electrical phenomena tended to increase in amplitude (tracing 3), after which a tendency to grouping occurred and a regular and rhythmic pattern was established (tracings 4 and 5). The trains of electrical discharges mostly had a duration of about 8 to $10 \mathrm{sec}$, whereas the intervals between them might show a larger variation; as a rule,

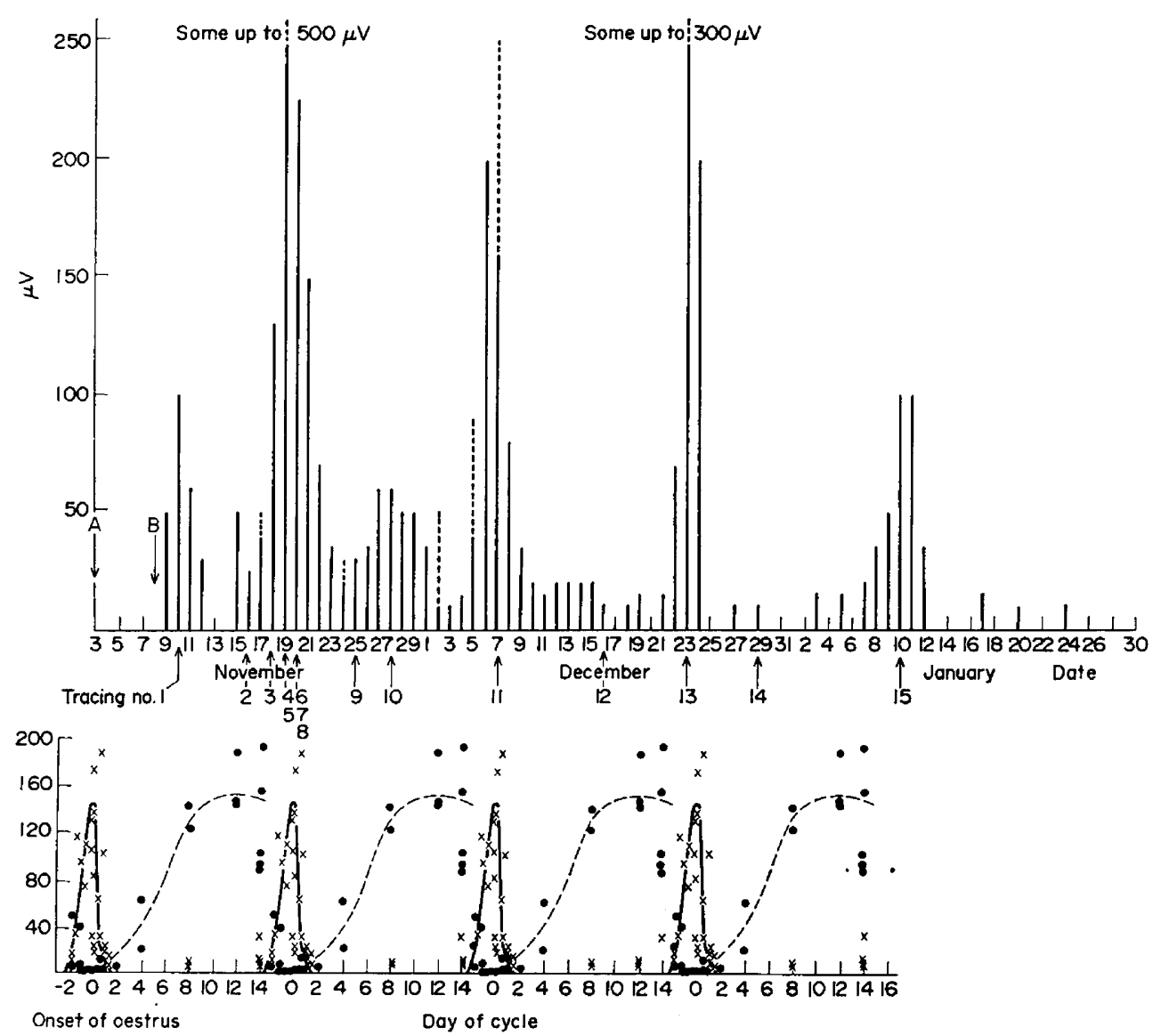

TEXT-FIG. 1. Upper part: the measured amplitudes $(\mu \mathrm{V})$ of electrical activity of the myometrium in Sheep no. 10 during the oestrous cycle. The dates of recording as well as the numbers of the reproduced curves (see Plates 2 to 5 ) are given on the horizontal axis. A, observed oestrus; B, date of operation. Lower part: concentration of oestradiol and progesterone in ovarian vein plasma of ewes during the oestrous cycle. $x-x$, oestradiol (ng/100 ml); Moore et al. (1969).

they lasted from 8 to $20 \mathrm{sec}$, but no longer intervals occurred. The trains of discharges were observed first at the tubal pair of electrodes and some seconds later at the electrodes situated near the corpus uteri (tracing 4). The burst of electrical activity passed over the uterine horn from the tubal end to the cervical end and was propagated over the entire horn in a period of 2 to $3 \mathrm{sec}$. This 
pattern was first recorded 17 days after the observed oestrus and thereafter, it occurred at regular intervals of 17 days (Text-fig. 1). On the next day, the pattern was similar but there were long periods of absolute quiescence which might last up to $5 \frac{1}{2}$ min (tracing 6 and 7). Often, the burst of activity was first seen near the corpus uteri and was propagated towards the tubal end (tracing 8 ). Thus, the direction of propagation seemed to be reversed.

During the next few days, there was a rapid decrease of the regular rhythmicity and the amplitudes of the myometrial electrical activity (tracings 9 and 10) after which the regular and rhythmic pattern returned and the amplitudes increased (tracing 11).

After a quiescent period (tracing 12), an active pattern (tracing 13), and a rest (tracing 14), a regular and active pattern was again recorded (tracing 15). From this description and the tracings, it is clear that a regular pattern and large amplitudes were closely related to each other, whereas during the periods with diffuse activity, or while the tracings showed only a few single spikes, the amplitudes were much smaller. In Text-fig. 1, the measured amplitudes are shown. It is clear that the large amplitudes occurred at 17-day intervals.

\section{DISCUSSION}

Until now, we have only spoken of the electrical phenomena observed in vivo in the sheep during the oestrous cycle, but it is obviously important to interpret these findings. Before contraction of a smooth muscle cell occurs, there is a depolarization of the cell membrane, which is followed by a repolarization. This event may be measured in the single cell by using microelectrodes. In this case, an action potential of about 50 to $60 \mathrm{mV}$ is measured. Our electrodes were much larger and picked up the potentials from the surface of several neighbouring cells. At the same time, inactive cells, depolarized cells and repolarizing cells can make contact with the electrode and they can therefore summate each other's effect or abolish it. With these electrodes, the total action potential's amplitude can never be measured, but quite a reliable reflection of the activity is recorded. The measured potentials have quite small amplitudes and, in most cases, do not represent the single spike of one cell. Many of the recorded spikes have several peaks, which is due to the combination of spikes (Sureau, Chavinié \& Cannon, 1965; Kao, 1967; Naaktgeboren, 1973). This is most clearly seen at high paper speeds (tracings 8 and 13). Only if the neighbouring cells 'fire' almost synchronously will the summation effect be possible and relatively larger spikes be recorded.

This will only happen if there is good coordination in the myometrial tissue. For this reason, it is easily understood that the regular rhythmic pattern is related to the large spikes.

A train of spikes represents a contraction of quite a large group of cells (for example, tracing 5), whereas single spikes in a small diffuse pattern represent local contractions of a single cell or of small groups of cells.

Thus we may conclude from our recordings that during the oestrous cycle in the ewe, the pattern of myometrial contractions changes. At 17-day intervals, a regular pattern of peristaltic contraction waves occurs. From the start of the 
contraction at the tube until its conclusion near the end of the uterine horn, a period of 10 to $12 \mathrm{sec}$ is usually measured. This was confirmed laparoscopically. On the next day, there are long pauses of absolute quiescence and periods of uterine activity during which, many contractions run antiperistaltically. After this day, the rhythmic pattern of propagated contractions rapidly disappears and only local and non-propagated contractions occur or the uterus may be almost completely quiescent. During this quiescent phase, a slight reappearance of rhythmic activity may be noticed (tracings 1 and 10) on some days.

According to Muurling (1971), the oestrous cycle in the Texel ewe has a mean duration of 17 days. The animals only come into oestrus during the period of September to February. During the rest of the year, they are in anoestrus. Ovulation most probably takes place just after cessation of oestrus-type behaviour. The duration of heat may vary between 1.6 and $47 \mathrm{hr}$. The most frequent duration is about $23 \mathrm{hr}$ and the mean durations of heat for several groups of ewes were found to be between 17 and $27 \mathrm{hr}$. Pro-oestrus has a mean duration of $6.8 \mathrm{hr}$ and metoestrus lasts about $5 \cdot 7 \mathrm{hr}$. Often, a silent oestrus occurs at the end of the oestrous season. Where this occurs, it is assumed that the ovaries do not produce enough oestrogen to evoke oestrous-type behaviour. If the data of Muurling (1971) are compared with our findings on myometrial activity, we can state that both oestrous-type behaviour and the continuous regular and rhythmic pattern of peristaltic contractions have a duration of about 1 day and occur at about 17-day intervals. It was only during this period that the ewes always accepted the ram and sometimes they also allowed the ram to mount during the beginning of the period in which long pauses and antiperistaltic waves started to occur.

It is obvious that the factors which are involved in establishing oestrous-type behaviour play an important rôle in causing the cyclical changes of myometrial activity.

The concentrations of circulating oestrogens and progesterone have been studied by Moore, Barret, Brown, Schindler, Smith \& Smyth (1969). The levels of circulating oestrogens reach their highest values on the day before the onset of heat. At the time of ovulation, oestrogens are not detectable in the ovarian venous blood (Text-fig. 1, lower part). Sometimes, a small additional oestrogen peak may occur on Days 6 to 8 of the cycle. During progesterone domination, the uterus is quiescent and the activity which has been described probably occurs just after the time of high oestrogen levels. It is most likely that tracing 1 and tracing 10 represent an increased activity due to an additional oestrogen peak. It is clear that the changes in the contraction pattern of the uterus are apparently caused by the changing progesterone/oestrogen ratio. It is widely accepted that progesterone inhibits the conduction properties of the myometrial cell membrane whereas oestrogens stimulate good conduction. If the conduction properties between neighbouring cells are optimal, firing is propagated very quickly and well coordinated contractions are initiated. Poor conduction permits only local contractions of small groups of muscle cells.

In the light of this, it appears from tracing 15 and Text-fig. 1 that the last peak of activity was less than that recorded earlier. It cannot, however, be excluded that this was a silent heat, i.e. ovulation without oestrous-type 
behaviour. The biological meaning of the different contraction patterns is difficult to discuss, since we have not yet enough data about ovulation time and mating in our animals.

The fact that the propagation of contraction waves spontaneously reverses from a peristaltic to an antiperistaltic direction may be given a functional interpretation. It could be of importance for the transport of semen after copulation. The subsequent disappearance of activity and the extreme quiescence in the middle of the cycle, i.e. at the time of implantation, are conditions which would favour the chances of the blastocyst to nidate.

Zerobin (1968), Döcke \& Worch (1963) and Döcke (1962) also indicate that the change of propagation direction is in favour of sperm transport. The factors which are responsible for this reversal are, at present, unknown.

\section{REFERENCES}

Döcke, F. (1958) Uteruskontraktionen beim Rind. Z. Zuchthygiene, 2, 266.

Döcke, F. (1962) Untersuchungen zur Uteruskontraktilität beim Rind. Arch. exp. VetMed. 16, 1205.

Döcke, F. \& WORCH, H. (1963) Untersuchungen über die Uterusmotilität und die Paarungsreaktionen der Sau. Z. Zuchthygiene, 7, 169.

KAO, C. Y. (1967) Ionic basis of electrical activity in uterine smooth muscle. In: Cellular Biology of the Uterus, chap. 11. Ed. R. M. Wynn. North Holland Publishing Co., Amsterdam.

Kelly, K. A., Code, C. F. \& Elveback, L. R. (1969) Patterns of canine gastric electrical activity. Am. F. Physiol. 217, 461.

Larks, S. D., Larks, G. G., Hoffer, R. E. \& Charlson, E. J. (1972) Electrical activity of oviducts in vivo. Nature, Lond. 234, 556.

Moawad, A. H. \& Bengtsson, L.Ph. (1967) In vivo studies of the motility patterns of the nonpregnant human uterus. I. The normal menstrual cycle. Am. F. Obstet. Gynec. 98, 1057.

Moore, N. W., Barret, S., Brown, J. B., Schindler, I., Smith, M. A. \& Smyth, B. (1969) Oestrogen and progesterone content of ovarian vein blood of the ewe during the oestrous cycle. $\mathcal{F}$. Endocr. 44, 55 .

MuUrLing, F. (1971) Oestriche en ovariële aktiviteit bij Texelse schapen in Nederland. (Oestrual and ovarian activity in Texel sheep in the Netherlands.) Thesis, Doctor Vet. Med. (with English summary), University of Utrecht.

NAAKTGEBOREN, C. (1973) Myometrial activity and its exploration by electromyography of uterine smooth muscle. In: Acta du Congrès d'Anaesthésie, Analgésie et Réanimation en Milieu Obstétrical, 1972. Librairie Annette, Paris (in press).

Sureau, C., Chavinit, J. \& Cannon, M. (1965) L'électrophysiologie utérine. Bull. Féd. Socs Gynéc. Obstét. Lang. fr. 17, 79.

Zerobin, K. (1968) Untersuchungen über die Uterusmotorik des Schweines. Zentbl. VetMed. 15A, 740. 